\title{
Chapter 8 \\ Acute Pulmonary Complications of Bone Marrow and Stem Cell Transplantation
}

\author{
Guang-Shing Cheng and David K. Madtes
}

\section{Introduction}

In the past two decades, advances in the techniques of bone marrow and stem cell transplantation as well as infectious prophylaxis and supportive care have improved the outcomes of patients with hematologic malignancies and other conditions who undergo these procedures [1]. Yet the overall success of hematopoietic cell transplantation (HCT) as life-prolonging therapy remains limited by pulmonary complications, a significant and vexing source of morbidity and mortality. The purpose of this chapter is to provide an overview of the epidemiology and diagnostic considerations of acute pulmonary complications as well as an updated review of specific disease entities or clinical situations in which acute respiratory failure can occur in this unique population of patients. The complications discussed will focus primarily on what is observed in recipients of allogeneic HCT.

For the context of this chapter, the term acute will be used to describe pulmonary complications of high acuity that would require immediate medical attention in an acute care setting or result in acute respiratory failure. Traditionally, HCT-related pulmonary disease is considered in the context of the time frame after HCT. Complications that occur within the first 100 days are often categorized as early-onset; after the first 100 days is considered to be late-onset [2]. Early-onset complications tend to be acute in presentation and are directly related to lung injury from the transplantation procedure or infections associated with immune reconstitution status. Most episodes of acute respiratory failure occur in the early period, but acute respiratory failure can occur any time after HCT. After day 100, noninfectious pulmonary disease predominates in the spectrum of HCT-related complications as manifestations of late-onset lung injury or chronic graft-versus-host disease. Some

G.-S. Cheng, MD $(\bowtie) \bullet$ D.K. Madtes, MD

Fred Hutchinson Cancer Research Center, University of Washington School of Medicine,

Seattle, WA, USA

e-mail: gcheng2@fredhutch.org; dmadtes@fredhutch.org 
patients experience acute respiratory failure as a consequence of these entities or from acute infections due to continued immunosuppression. There are several pulmonary syndromes that usually occur in the early post-HCT period, but can occasionally cause respiratory compromise in long-term survivors.

Outcomes of respiratory failure in a contemporary era of transplantation may be improving due to reduced incidence of severe lung injury and improvements in prophylaxis and supportive care [1]. Nonetheless, respiratory failure due to a variety of causes continues to account for the majority of the serious and fatal early complications after HCT.

\section{Acute Respiratory Failure After HCT}

\section{Epidemiology of Acute Respiratory Failure}

Approximately $15-25 \%$ of HCT recipients require ICU admission. Respiratory failure is the most common indication, historically as well as in contemporary practice, affecting $60 \%$ or more of HCT recipients in the ICU [3]. Acute respiratory failure occurs more frequently in allogeneic recipients compared with autologous recipients. Patients at highest risk for acute respiratory failure requiring mechanical ventilation include those who have a reduced pretransplant $\mathrm{FEV}_{1}$ or have undergone myeloablative conditioning [4].

Overall, the prognosis of HCT recipients who experience respiratory failure and require mechanical support is poor. Rubenfeld and Crawford proposed an argument for withdrawal of ventilatory support based on a nested case-control study in which the combination of lung injury requiring mechanical ventilation, elevated liver function enzymes, renal dysfunction, and vasopressor support was $100 \%$ predictive of death [5]. This message was tempered by the finding that overall survival of mechanically ventilated patients improved from 5 to $16 \%$ in the last 5 years of their study, which took place between the years 1980 and 1992.

Since this influential article was published nearly 20 years ago, there have been significant advances in ICU care which have improved survival in critically ill patients [6]. A low tidal volume ventilation strategy, in which end-inspiratory plateau pressures are limited to reduce barotrauma and further lung injury, was shown to decrease the mortality from adult respiratory distress syndrome (ARDS) by $22 \%$ as compared to conventional ventilatory settings [7]. Early goal-directed therapy for sepsis as well as an emphasis on prompt empiric antibiotic administration directly impact survival of patients with severe sepsis and circulatory shock [8]. Additional attention to supportive care measures such as aspiration precautions, reduction of sedation, and prevention of iatrogenic complications have likely contributed to improvement in ICU outcomes. HCT-specific factors such as nonmyeloablative conditioning regimens have become more widespread in use, reducing initial toxicities. The incidence of acute GVHD has declined due to prophylactic strategies, and infectious prophylaxis has decreased the incidence of severe early infectious complications [1]. 
Several recent studies have shown a modest improvement in outcomes of HCT recipients admitted to the ICU including those who require mechanical ventilation [9-11]. In a multicenter retrospective study in France, ICU hospital mortality decreased from 67 to $48 \%$ from 1997-2003 to 2004-2011. Three month mortality of the subgroup requiring mechanical ventilation decreased from 84 to $70 \%$ [11]. Although no longer considered futile, mechanical ventilation remains a significant independent risk factor for mortality in the ICU. Associated organ dysfunction, including shock and liver failure, also remain independent predictors of death [12].

\section{Diagnostic Considerations}

The differential diagnosis of acute respiratory failure after HCT is broad and depends on the timing of onset after HCT (Fig. 8.1) [2]. Early after HCT, direct noninfectious complications of the conditioning procedure including volume overload-related pulmonary edema or congestive heart failure and severe mucositis leading to aspiration pneumonitis should always be considered. Idiopathic pneumonia syndrome (IPS), pre-engraftment syndrome, diffuse alveolar hemorrhage (DAH), delayed pulmonary toxicity syndrome (DPTS), and acute fibrinous and organizing pneumonia (AFOP) represent forms of lung injury on a spectrum of histopathologic findings that are specific to the transplantation procedure. The etiology of infectious complications is related to the nature and degree of immunocompromise from the patient's engraftment status and pharmacologic immunosuppression.

These noninfectious etiologies must be distinguished from infectious complications in order to tailor antimicrobial therapy and to guide decisions to empirically augment immunosuppression. Computed tomography (CT) of the chest is mandatory in initial evaluation of respiratory failure, and radiographic patterns may suggest specific etiologies. The differential diagnosis of focal or diffuse infiltrates is broad, and further evaluation is usually undertaken.

Fiberoptic bronchoscopy with bronchoalveolar lavage (BAL) is a minimally invasive modality which is relied upon to make a specific diagnosis for new onset pulmonary infiltrates. The utility of bronchoscopy lies in exclusion of infection when clinical suspicion for a noninfectious etiology is high as much as it is to establish a specific infectious etiology [13]. The diagnostic yield of BAL has improved significantly for specific infectious diagnoses due to the advancements in diagnostic testing, including CMV rapid shell vial culture, aspergillus galactomannan, and respiratory viral PCR panel (Table 8.1) [14]. Two retrospective studies done in the era of routine anti-infective prophylaxis against fungus, CMV, and Pneumocystis jirovecii, report the yield of fiberoptic bronchoscopy for a specific diagnosis is $34-50 \%$, with a higher yield for allogeneic HCT $[15,16]$. The majority of the diagnoses are achievable by BAL alone, with transbronchial biopsy adding additional specific information in $<10 \%$ of cases.

While aggressive diagnostic workup is appropriate for HCT patients, the impact of BAL on patient outcomes is difficult to ascertain [13]. Various factors including the 


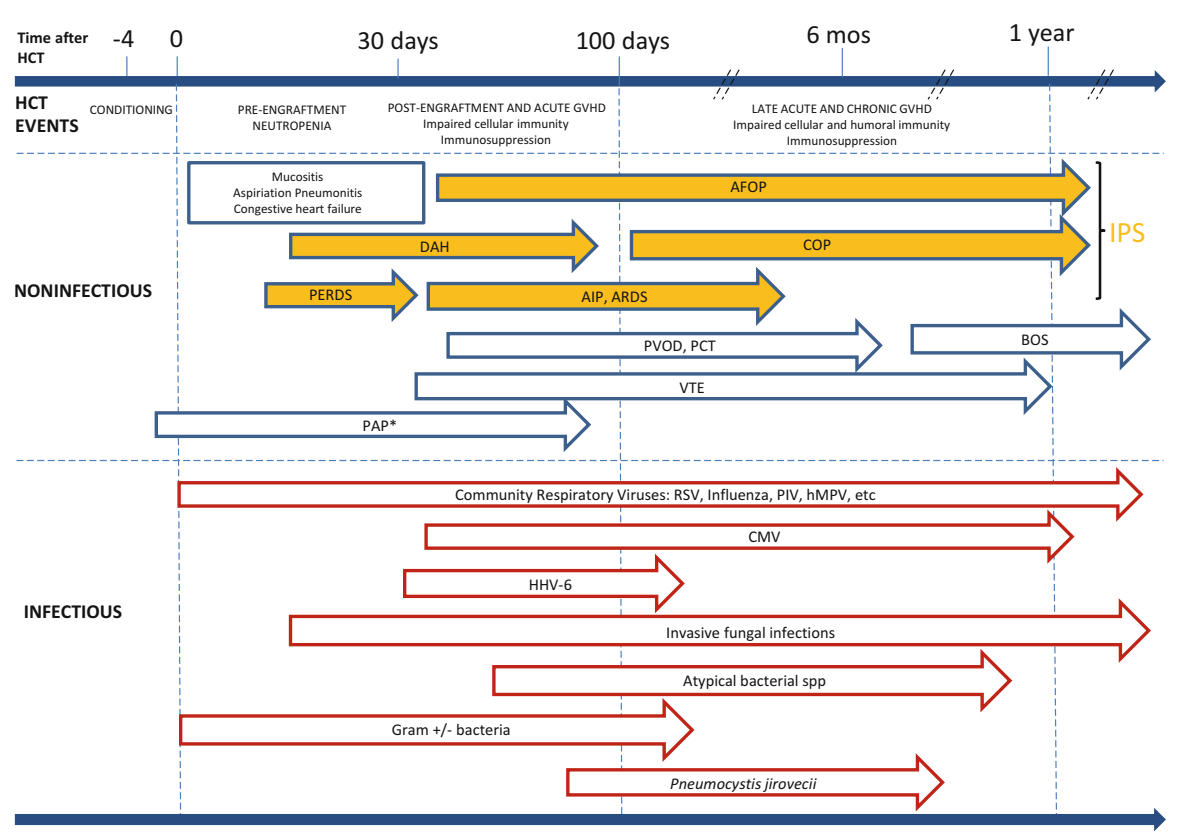

Fig. 8.1 Timeline of infectious and noninfectious pulmonary complications after allogeneic hematopoietic cell transplantation. AFOP acute fibrinous and organizing pneumonia, AIP acute interstitial pneumonitis, $A R D S$ acute respiratory distress syndrome, $B O S$ bronchiolitis obliterans syndrome, $C O P$ cryptogenic organizing pneumonia, $C M V$ cytomegalovirus, $G V H D$ graft-versushost disease, $H H V-6$ human herpesvirus-6, $H M P V$ human metapneumovirus, PAP pulmonary alveolar proteinosis, $P C T$ pulmonary cytolytic thrombi, $P I V$ parainfluenza virus, $P V O D$ pulmonary veno-occlusive disease, $P E R D S$ peri-engraftment respiratory distress syndrome, $V T E$ venous thromboembolism, $R S V$ respiratory syncytial virus. *PAP has been reported to occur $>1$ year postHCT. Adapted from Ref. [13]

timing of procedure may influence the clinical outcome, as patients are often referred for BAL after persistence or progression of disease on empiric antibiotic therapy. A large retrospective study of 501 consecutive patients who underwent 598 BALs for the evaluation of new pulmonary infiltrates and suspected pneumonia during the first 100 days after HCT showed that the yield of BAL for clinically significant pathogens was 2.5 -fold higher $(p<0.0001)$ if performed within the first 4 days of presentation, compared to those performed late, and that the yield was highest when performed within $24 \mathrm{~h}$ of presentation. Mortality at 30 and 100 days following the BAL was significantly lower when a diagnosis of infection was confirmed by early BAL compared to late BAL, which was associated with multidrug-resistant and polymicrobial infections [17]. These findings suggest that BAL should be used in the early evaluation of HCT recipients with pulmonary infiltrates, as opposed to a conservative, expectant approach of bronchoscopy only after the failure of empiric therapy.

The use of bronchoscopy has largely supplanted surgical biopsy as means of diagnosing unknown lung disease in HCT patients. When treatment decisions depend on a definitive diagnosis of a noninfectious etiology and when empiric ther- 
Table 8.1 Laboratory evaluation of bronchoalveolar lavage specimens for specific infectious agents

\begin{tabular}{|c|c|c|c|c|}
\hline & Bacterial & Fungal & Viral & Parasitic \\
\hline Pathologic exam & $\begin{array}{l}\text { Wright-Giemsa } \\
\text { Papanicolaou's } \\
\text { Modified } \\
\text { Jimenez stain } \\
\text { (Legionella) }\end{array}$ & $\begin{array}{l}\text { Silver stain } \\
\text { (Pneumocystis } \\
\text { jirovecii) } \\
\text { Fungal hyphae } \\
\text { Yeast forms }\end{array}$ & $\begin{array}{l}\text { Viral inclusions } \\
\text { (CMV) }\end{array}$ & \begin{tabular}{|l} 
Larval forms \\
(Strongyloides)
\end{tabular} \\
\hline $\begin{array}{l}\text { Microbiology- } \\
\text { stains }\end{array}$ & $\begin{array}{l}\text { Gram stain } \\
\text { Acid fast } \\
\text { Modified acid } \\
\text { fast }\end{array}$ & $\begin{array}{l}\text { Wet mount } \\
\text { KOH } \\
\text { Calcofluor white } \\
\text { stain }\end{array}$ & & \\
\hline Culture & $\begin{array}{l}\text { Aerobic and } \\
\text { anaerobic } \\
\text { Chocolate yeast } \\
\text { extract } \\
\text { (Legionella) } \\
\text { Acid-fast } \\
\text { Nocardia } \\
\text { Actinomycoses }\end{array}$ & Fungal & $\begin{array}{l}\text { Routine viral } \\
\text { culture } \\
\text { Rapid } \\
\text { centrifugation } \\
\text { "shell vial" } \\
\text { (CMV, RSV) }\end{array}$ & \\
\hline Immunoassay & $\begin{array}{l}\text { DFA } \\
\text { (Legionella) }\end{array}$ & $\begin{array}{l}\text { ELISA for } \\
\text { galactomannan } \\
\text { IFA/DFA } \\
\text { (Pneumocystis } \\
\text { jirovecii) }\end{array}$ & $\begin{array}{l}\text { DFA } \\
\text { (influenza) } \\
\text { DFA (CMV) }\end{array}$ & $\begin{array}{l}\text { Immunostain } \\
\text { (Toxoplasma) }\end{array}$ \\
\hline $\begin{array}{l}\text { Molecular } \\
\text { diagnostics: PCR }\end{array}$ & $\begin{array}{l}\text { Chlamydia } \\
\text { Mycoplasma }\end{array}$ & $\begin{array}{l}\text { Aspergillus } \\
\text { Pan-fungal } \\
\text { (including } \\
\text { Mucorales spp. }\end{array}$ & $\begin{array}{l}\text { Herpesviruses: } \\
\text { CMV, EBV, } \\
\text { HSV, VZV, } \\
\text { HHV-6 } \\
\text { CRVs: } \\
\text { RSV, influenza, } \\
\text { PIV-3, hMPV, } \\
\text { rhinovirus, } \\
\text { bocavirus, } \\
\text { adenovirus } \\
\text { Coronavirus }\end{array}$ & Toxoplasma \\
\hline
\end{tabular}

apy is risky, surgical lung biopsy may be required to achieve a specific diagnosis, as is that case for pulmonary venoocclusive disease and pulmonary cytologic thrombi, for example. Surgical lung biopsy has the advantage of direct visualization of the biopsy site, as well as obtaining a large enough piece of tissue that allows for histologic examination and culture. Bleeding in the setting of thrombocytopenia can be controlled directly. In contemporary practice surgical lung biopsy is usually performed videoscopically (video assisted thoracic surgery, or VATS), which theoretically reduces the morbidity associated with thoracotomy. Lung biopsy in this population must be carefully considered, as the morbidity of surgery in the setting of neutropenia, thrombocytopenia and/or respiratory failure may be unacceptably high, particularly if the overall prognosis is poor and specific therapy is unlikely to alter the outcome. White and colleagues at Memorial Sloan Kettering Cancer Center 
reviewed 67 open lung biopsies in 63 patients with hematologic malignancies from 1996 to 1998, including 25 bone marrow transplant patients, and found that a specific diagnosis was found in $41(62 \%)$ of the biopsies. Focal lesions were much more likely than diffuse lesions to yield a specific diagnosis (79\% vs. $36 \%$ ), and neutropenic or mechanically ventilated patients had a low likelihood of having a specific diagnosis. The risk of complications was significant, affecting $13 \%$ of the biopsies, including 1 death [18].

In contrast to classic reports in bone marrow transplant recipients prior to the era of CMV and fungal prophylaxis [19, 20], infectious etiologies are no longer the most common diagnoses at lung biopsy: inflammatory conditions were the most common specific diagnoses (23\%), followed by infection (21\%) and malignancy (18\%) [18]. The likelihood of an HCT recipient undergoing a surgical lung biopsy has continued to decline in the past two decades, and infectious etiologies at lung biopsy, particularly invasive aspergillosis, are significantly less likely than a noninfectious etiology, likely due to the introduction of broad spectrum triazole therapy against invasive fungal infection in the early 2000s [21]. A recent meta-analysis showed that the overall yield of a specific diagnosis was similar between BAL and surgery (53\% vs. $54 \%$ ), with a complication rate of 8 and $15 \%$ for BAL and surgery, respectively. The proportion of noninfectious diagnosis exceeded the infectious diagnoses with surgical biopsy [22].

\section{Noninfectious Etiologies}

\section{Lung Injury Syndromes, Early Onset}

\section{Idiopathic Pneumonia Syndrome}

A spectrum of acute lung injuries can develop in the early posttransplantation period that fall under the category of the idiopathic pneumonia syndrome (IPS), and includes diffuse alveolar hemorrhage, peri-engraftment syndrome, delayed pulmonary toxicity syndrome and acute fibrinous and organizing pneumonia (Table 8.2). Broadly defined as widespread alveolar injury seen after HCT in the absence of active lower respiratory tract infection, cardiac dysfunction, acute renal failure, or iatrogenic fluid overload, IPS is thought to result from a variety of lung insults including toxic effects of the HCT conditioning regimen, immunologic cellmediated injury, inflammatory cytokines, and occult pulmonary infections [2]. With the increasing use of new diagnostic methods such as multiplex PCR for respiratory viruses and the biomarker galactomannan for Aspergillus spp., the incidence of acute lung injury secondary to pulmonary infection has increased. Seo et al. have shown that approximately half of patients with IPS had pathogens detected in the BAL when these newer diagnostic methods were employed and that pathogen detection was associated with increased mortality. The most frequent pathogens were human herpes virus-6 (HHV-6), human rhinovirus (HRV), cytomegalovirus (CMV), 
Table 8.2 The spectrum of clinical lung injury entities after HCT classified under IPS

\begin{tabular}{l|l|l|l|l}
\hline Clinical entity & $\begin{array}{l}\text { Timing of onset } \\
\text { after HCT }\end{array}$ & Histology & $\begin{array}{l}\text { Diagnostic } \\
\text { considerations }\end{array}$ & Prognosis \\
\hline $\begin{array}{l}\text { Acute fibrinous } \\
\text { organizing } \\
\text { pneumonia } \\
\text { (AFOP) }\end{array}$ & Early or late & $\begin{array}{l}\text { Intra-alveolar } \\
\text { fibrin, organizing } \\
\text { pneumonia and } \\
\text { type II pneumocyte } \\
\text { hyperplasia }\end{array}$ & Poor \\
\hline $\begin{array}{l}\text { Acute interstitial } \\
\text { pneumonia } \\
\text { (AIP) }\end{array}$ & $2-6$ mos & $\begin{array}{l}\text { Diffuse alveolar } \\
\text { damage }\end{array}$ & Poor \\
\hline $\begin{array}{l}\text { Acute } \\
\text { respiratory } \\
\text { distress } \\
\text { syndrome } \\
\text { (ARDS) }\end{array}$ & $2-6$ mos & $\begin{array}{l}\text { Diffuse alveolar } \\
\text { damage }\end{array}$ & Poor \\
\hline $\begin{array}{l}\text { Cryptogenic } \\
\text { organizing } \\
\text { pneumonia } \\
\text { (COP) }\end{array}$ & $2-12$ mos & $\begin{array}{l}\text { Patchy plugs of } \\
\text { granulation tissue } \\
\text { and macrophages } \\
\text { in distal airways } \\
\text { and alveoli }\end{array}$ & $\begin{array}{l}\text { Chest CT: Ground } \\
\text { glass \& linear } \\
\text { opacities, upper } \\
\text { lobe predominance }\end{array}$ & Favorable \\
\hline $\begin{array}{l}\text { Diffuse alveolar } \\
\text { hemorrhage } \\
\text { (DAH) }\end{array}$ & $<1$ mo-3 mos & $\begin{array}{l}\text { Diffuse alveolar } \\
\text { damage; intra- } \\
\text { alveolar red blood } \\
\text { cells and } \\
\text { hemosiderin-laden } \\
\text { macrophages }\end{array}$ & $\begin{array}{l}\text { Progressively } \\
\text { bloodier BAL fluid }\end{array}$ & Poor \\
\hline $\begin{array}{l}\text { Peri-engraftment } \\
\text { respiratory } \\
\text { distress } \\
\text { syndrome } \\
\text { (PERDS) }\end{array}$ & $\begin{array}{l}\text { Within 5-7 days } \\
\text { of neutrophil } \\
\text { engraftment }\end{array}$ & $\begin{array}{l}\text { Dype II } \\
\text { pneumocyte } \\
\text { hyperplasia, septal } \\
\text { thickening, } \\
\text { interstitial fibrosis, } \\
\text { small vessel } \\
\text { endothelial injury }\end{array}$ & $\begin{array}{l}\text { Autologous } \\
\text { transplants only }\end{array}$ & Favorable \\
\hline $\begin{array}{l}\text { Delayed } \\
\text { pulmonary } \\
\text { toxicity } \\
\text { syndrome } \\
\text { (DPTS) }\end{array}$ & $1-6$ mos & $\begin{array}{l}\text { Neutrophilic } \\
\text { inflammation on } \\
\text { BAL }\end{array}$ & Favorable \\
\hline
\end{tabular}

and Aspergillus spp. [23]. Of note, HHV-6, like CMV, is in the human $\beta$-herpesvirus family and latently infects $95 \%$ of healthy adults. HHV-6 has been shown to reactivate frequently in critically ill patients, but its specific role in the pathogenesis of respiratory disease and outcomes in critical illness remains unknown [24].

IPS has been classified into specific entities based in large part on the presumed site of primary tissue injury. The primary anatomical sites of inflammation and dysfunction are divided into three subtypes: (1) pulmonary parenchymal, (2) vascular endothelial, and (3) airway epithelial [25]. Each subtype is further classified into distinct entities of noninfectious acute lung injury. While some IPS cases 
remain unclassified, this classification scheme may facilitate the development of therapeutic interventions that can be directed toward distinct subtypes of disease [25] (Table 8.2).

An association between IPS and acute GVHD has been reported, but the specific role of alloreactive donor T lymphocytes in the pathogenesis of IPS remains unclear. Although identified in the lungs of some patients with IPS, epithelial apoptosis, considered pathognomonic for acute GVHD, has not been consistently detected in allogeneic HCT recipients with acute lung dysfunction. There is no pathognomonic histologic finding that defines IPS [25], as the histology depends upon the anatomic site of injury. The diagnosis of IPS is rarely confirmed by tissue biopsy given the significant risks of open lung biopsy in this population and the low yield of lung tissue by transbronchial biopsy via fiberoptic bronchoscopy recovered from HCT patients with acute lung injury. The diagnosis of IPS is usually one of exclusion in the appropriate clinical context; BAL is often performed to exclude infection.

The cumulative incidence of IPS after allogeneic HCT ranges from $2.2 \%$ following nonmyeloablative conditioning to $8.4 \%$ following conventional, full-intensity radiation containing preparative regimens [26]. The median time of onset after allogeneic HCT is 19 days (range, 4-106 days) with mortality rates ranging from 60 to $80 \%$ overall to greater than $95 \%$ for patients requiring mechanical ventilation. Although IPS also develops after autologous HCT, the incidence is lower, the median time to onset is generally later (63 days; range 7-336 days), the response to corticosteroids is usually prompt and the prognosis is favorable compared with IPS in allogeneic HCT recipients.

Risk factors for IPS after allogeneic HCT include full-intensity conditioning with total body irradiation, acute GVHD, older recipient age, an underlying diagnosis of acute leukemia or myelodysplastic syndrome and the number of platelet transfusions administered [27]. Risk factors for IPS following autologous HCT include older patient age, severe oral mucositis, conditioning regimens using total body irradiation or carmustine (BCNU), chest irradiation within 2 weeks before transplant, female gender, and an underlying diagnosis of solid tumor [2, 25].

Current standard treatment strategies of IPS include broad-spectrum antibiotics and IV corticosteroids and supportive care with lung protective mechanical ventilation and venovenous ultrafiltration for those with respiratory failure. Response to corticosteroids ( $\leq 2 \mathrm{mg} / \mathrm{kg} /$ day) has shown mixed efficacy in allogeneic HCT recipients, which likely reflects the diversity of underlying causes responsible for the lung insult. Compared with lower doses, higher doses of corticosteroid therapy ( $>2 \mathrm{mg} / \mathrm{kg} /$ day) have not been shown to improve outcome but are associated with increased iatrogenic complications including fungal infection [26, 28]. Prophylaxis against filamentous fungal infection with voriconazole or micafungin is recommended during treatment with corticosteroids $(\geq 0.5 \mathrm{mg} / \mathrm{kg} / \mathrm{day})$ because fungal pneumonia was identified in $16 \%(4 / 25)$ of IPS patients at the time of autopsy in a single-center study.

Preclinical and clinical studies suggest that neutralization of tumor necrosis factor (TNF)- $\alpha$ may be a useful therapeutic strategy for IPS. In a multicenter, Phase II single-arm, open-label study by Yanik and colleagues in pediatric HCT recipients, treatment with etanercept $(0.4 \mathrm{mg} / \mathrm{kg} / \mathrm{dose}$ twice weekly for 8 doses $)$ 


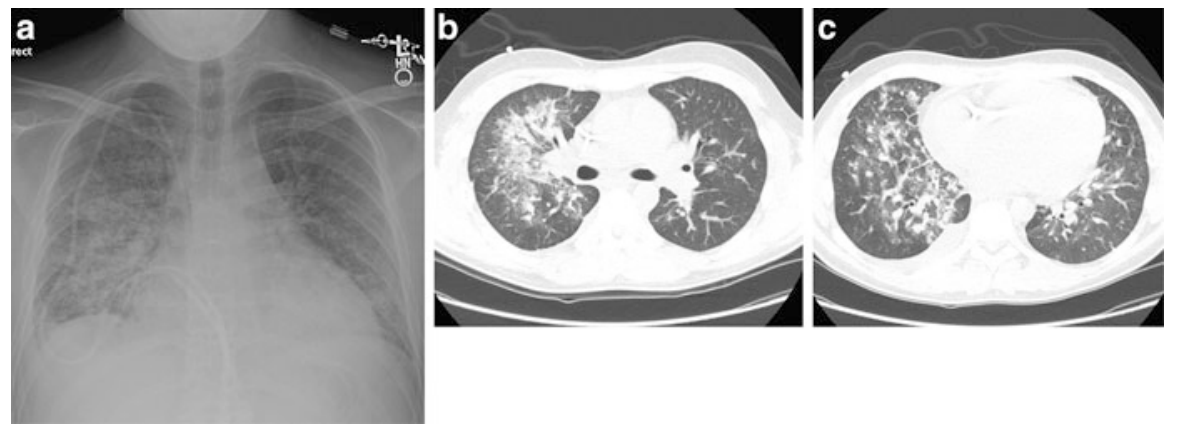

Fig. 8.2 DAH in a patient 23 days following an allogeneic stem cell transplant with new onset hemoptysis and respiratory insufficiency. DAH was diagnosed by bronchoscopy which showed progressively bloodier lavage fluid. (a) Chest radiograph shows patchy consolidation. (b, c) Chest CT shows diffuse ground glass opacities with areas of denser consolidation within a peribronchial vascular distribution

plus corticosteroids ( $2 \mathrm{mg} / \mathrm{kg} / \mathrm{day}$ ) resulted in a complete response in $71 \%$ (20 of 28) of patients and was associated with a high overall survival compared with historical controls [29]. In a randomized, double-blind, placebo-controlled trial of corticosteroids ( $2 \mathrm{mg} / \mathrm{kg} /$ day) with etanercept $(0.4 \mathrm{mg} / \mathrm{kg} / \mathrm{dose}$ twice weekly for 8 doses) or placebo for the treatment of IPS, the use of corticosteroids was associated with higher response rates (defined as alive with complete discontinuation of supplemental oxygen support at days 28 and 54 after initiation of therapy) and overall survival compared to historical controls, but the addition of etanercept did not lead to further increases in response [30]. This study was truncated early and the small sample size precluded a definitive conclusion regarding the benefit of etanercept therapy.

Diffuse alveolar hemorrhage (DAH), also called acute pulmonary hemorrhage or hemorrhagic alveolitis, is a common subset of IPS that generally develops in the immediate post-transplant period and is characterized by progressive dyspnea, cough, and hypoxemia with or without fever and diffuse bilateral pulmonary infiltrates (Fig. 8.2). The cumulative incidence of DAH is 5-12\% of HCT patients with a median time of onset of 19 days (range, 5-34 days) in allogeneic recipients and 12 days (range, 0-40 days) in autologous patients. The diagnosis is based on progressively bloodier return of BAL fluid. Treatment of DAH consists of aggressive platelet support to maintain a platelet count greater than or equal to 100,000 and high-dose systemic corticosteroids ( $2 \mathrm{mg} / \mathrm{kg} /$ day to $1 \mathrm{~g} / \mathrm{m}^{2} /$ day). The addition of aminocaproic acid or recombinant factor VII may further improve outcomes. Despite these interventions, the mortality from DAH ranges from 60 to $100 \%$ with death usually due to multiorgan failure within 3 weeks of diagnosis [2].

Peri-engraftment respiratory distress syndrome (PERDS) develops within 5-7 days of engraftment and accounts for $33 \%$ of IPS cases after allogeneic HCT. Although the clinical presentation of PERDS after HCT is similar to other subsets of IPS, lung dysfunction is more responsive to corticosteroids and the prognosis is better [31]. 
The incidence of delayed pulmonary toxicity syndrome (DPTS) is 29-64\% in autologous HCT recipients receiving chemotherapy with regimens containing BCNU, cyclophosphamide, and cisplatin. The median time of onset is 45 days (range, 21-149 days), and treatment with corticosteroids (1 mg/kg/day) results in resolution in up to $92 \%$ of cases [32].

Acute fibrinous and organizing pneumonia (AFOP) is an infrequently observed subset of IPS that is histologically characterized by the presence of intra-alveolar fibrin that form fibrin "balls" within the alveolar spaces, organizing pneumonia composed of intraluminal loose connective tissue within alveolar ducts and bronchioles in association with the fibrin and type II pneumocyte hyperplasia, typically in a patchy distribution. AFOP has been associated with a variety of disease states, including HCT [33], infections, rheumatologic diseases as well as environmental and drug exposures. The presenting symptoms may include fever, cough, dyspnea, hemoptysis, malaise, arthralgias, and chest, pleural, or abdominal pain. Two distinct clinical courses have been reported: (1) an acute and fulminant course typically leading to respiratory failure and death and (2) a less severe, subacute course. The radiographic findings of patients with an acute presentation and rapid decline are similar to those of diffuse alveolar damage including diffuse but basilar predominant consolidation and ground glass opacities. The radiographic features of patients with subacute AFOP are indistinguishable from those of organizing pneumonia with both focal and diffuse parenchymal abnormalities. Although no specific therapy exists, case reports describe response to corticosteroids [34] and immunosuppressant therapy [35].

\section{Lung Injury Syndromes, Late Onset}

\section{Cryptogenic Organizing Pneumonia}

Cryptogenic organizing pneumonia (COP), originally given the term bronchiolitis obliterans organizing pneumonia (BOOP), was first described by Epler in 1985 as a distinct clinicopathologic entity that can affect the general population. As a histologic entity, organizing pneumonia (OP) may be associated with bacterial and viral infections, but most OP in the general population is idiopathic, hence the term cryptogenic organizing pneumonia (COP). In HCT recipients, the histology is characterized by patchy plugs of granulation tissue occupying distal terminal airways, alveolar ducts and alveolar sacs, widened alveolar septa and mononuclear cell infiltration, and accumulation of foamy macrophages within alveoli (Fig. 8.3) [36]. In the context of noninfectious pulmonary entities after HCT, COP may be considered a late-onset manifestation on one end of the spectrum of lung injury syndromes, of which IPS occupies the early onset, acute end of the spectrum [37].

In an analysis of 49 biopsy-proven cases of COP after allogeneic HCT, there was a significant association with the presence of acute or chronic graft-versus-host disease (GVHD) by multivariate analysis. Of note, the severity of the GVHD, acute or 

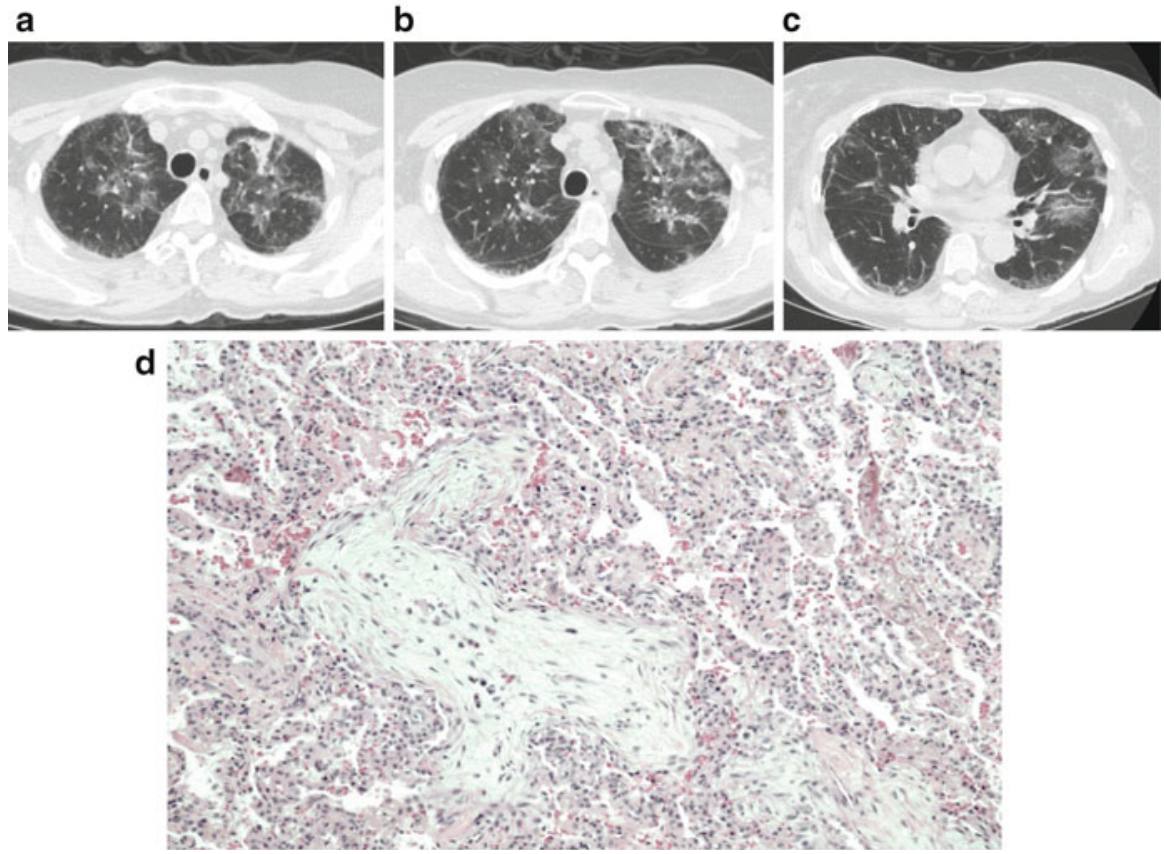

Fig. 8.3 COP after HCT. (a-c) Serial Chest CT images in the same individual showing upper lobe predominant reticular linear and ground glass opacities. (d) Example of COP on lung biopsy showing patchy plugs of granulation tissue within distal small airways and alveolar spaces with macrophages and inflammatory infiltrate. Courtesy of Drs. Robert Hackman and David Myerson

chronic, was significantly greater in patients with COP compared with controls, and $22 \%$ of the cases were diagnosed in the setting of corticosteroid taper for GVHD [36]. The association with severe acute GVHD and extensive chronic GVHD in survivors beyond day 100 was also shown in a large retrospective study of 193 HCT recipients from a Japanese registry of 9550 allogeneic HCT recipients. Other risk factors that were shown to be associated with COP included donor HLA disparity, female-to-male HCT, related peripheral blood stem cell transplantation and radiation as part of a myeloablative conditioning regimen [38]. Although an alloimmune mechanism may be postulated from the reported association with GVHD, there is currently no direct evidence of a donor T-cell-mediated immune response against lung tissue in this entity.

The clinical presentation of COP after HCT is similar to that in other clinical settings: fever, cough, and progressive dyspnea arising in a subacute to acute tempo. The median time of onset in allogeneic HCT recipients is approximately 3 months after transplant, although many cases are diagnosed after day 100 and in long-term survivors up to several years after transplant. Since the presentation may be subacute and insidious, many patients are diagnosed in the outpatient setting, but the disease can progress to acute respiratory failure necessitating ventilator support. In the aforementioned case series, the median time to diagnosis was 108 days after 
HCT (range 5-2819 days), after a median symptom duration of 13 days. Pulmonary function testing may reveal a new restrictive defect $(43 \%)$, obstructive defect $(11 \%)$, mixed restrictive and obstructive defect $(8 \%)$, or normal physiology $(38 \%)$. Sixty-four percent had a new diffusing capacity deficit [36]. The radiographic hallmark of COP on chest CT is ground glass opacities, with linear opacities in an upper lobe, often bilateral, distribution (Fig. 8.3). Features of biopsy-proven COP on chest CT include ground glass opacities (94\%), consolidation (50\%), and linear opacities $(50 \%)$ with an upper lobe predominance $(63 \%)$ [39]. These linear opacities are usually not described in COP that occurs in non-HCT settings. Because the radiographic findings as well as the clinical presentation may mimic infectious pneumonia, bronchoscopy with lavage is recommended to exclude infectious etiologies. In cases in which a clinical diagnosis is still unclear, a histologic diagnosis by surgical lung biopsy may be warranted.

The mainstay of treatment for COP after HCT is corticosteroids, usually initiated at a dose of $0.5-1.0 \mathrm{mg} / \mathrm{kg} / \mathrm{day}$, depending on the severity. If the patient has severe disease or is in acute respiratory failure, administration of pulse steroids with 1-2 $\mathrm{g}$ initial dosing is justified. Recent recommendations suggest treating with corticosteroids starting at $0.75 \mathrm{mg} / \mathrm{kg} /$ day until symptomatic or radiographic improvement is noted then tapering slowly over a minimum of 4-6 months [40]. Although there is little more than anecdotal evidence for the use of macrolides in this population, chronic clarithromycin or azithromycin may be added as an adjunctive immunomodulatory agent in patients who have difficulty tapering or tolerating corticosteroids [41].

Overall, prognosis for COP after HCT is good, with a majority of cases resolving or stabilizing with corticosteroids. Relapse is common, particularly when corticosteroid taper is accelerated. A small, but significant proportion of patients will progress in spite of therapy and ultimately succumb to respiratory failure. In refractory cases, it is hypothesized that the interstitial inflammation sets up a process of progressive interstitial fibrosis, evidenced by progressive interstitial changes on computed tomography. It is not known what factors contribute to progression, or which individuals are at risk for progression. As more patients survive past day 100 after allogeneic HCT, there is a sense amongst transplant physicians that COP is increasing in frequency, but the true incidence is difficult to ascertain given the relative rarity of the condition and histologic confirmation by lung biopsy is now rarely undertaken. Investigation into this entity and its impact on HCT outcomes and nonrelapse mortality is warranted.

\section{Bronchiolitis Obliterans Syndrome}

Bronchiolitis obliterans syndrome (BOS) is a late-onset and chronic pulmonary problem, but it is considered here because acute respiratory failure can occur in the setting of rapid airflow decline and infectious complications. BOS is characterized by new onset irreversible airflow obstruction in the setting of prior or active chronic graft-versus-host disease and usually occurs within the first 2 years after 
HCT. Although the pathogenesis of BOS is unknown, it is likely a form of lung injury caused by an alloimmune response to the airway epithelium. An aberrant repair response results in the obliteration of small airways with fibrous material, which leads to the physiologic correlate of airways obstruction [42]. The clinical manifestations of BOS are usually insidious, but there is a phenotype of rapidly progressive airflow obstruction which can lead to primary respiratory failure [43]. Even when patients with BOS are stabilized, morbidity and mortality from BOS are high, and result mainly from infectious pneumonia or progressive chronic respiratory failure [42].

\section{Drug-Induced Pneumonitis}

Individual components of some conditioning regimens used in HCT are associated with pulmonary toxicity. Carmustine (or bischloroethylnitrosourea, BCNU), used as a single agent or in combination prior to autologous HCT for solid tumor and hematologic malignancies, is associated with acute onset pneumonitis with an incidence of 4-59\%. Prior mediastinal radiation therapy, BCNU dose greater than $1000 \mathrm{mg}$ and age less than 54 were independent risk factors for developing pneumonitis after autologous HCT for lymphoma [44]. The mechanism of BCNU-associated pulmonary toxicity has not been entirely elucidated but is thought to include oxidative stress, glutathione dysfunction and immune-mediated lung injury [45].

Cyclophosphamide is another agent used in combination with total body radiation or other chemotherapy agents in preparative regimens for autologous and allogeneic HCT that is associated with pulmonary toxicity thought to be related to increased reactive oxygen species generation and depletion of glutathione stores [46].

A spectrum of drug-induced lung diseases has been reported after transplantation in association with immunosuppressive therapies. Implicated immunosuppressive agents and their patterns of pulmonary toxicity are listed in Table 8.3. Noncardiogenic pulmonary edema and ARDS have been reported in association with intravenous and oral cyclosporine after bone marrow transplantation that resolves when the medication is discontinued and is postulated to be an idiosyncratic reaction [2].

The mammalian target of rapamycin (mTOR) inhibitor, sirolimus, binds to rapamycin-FK binding protein-12 to inhibit $\mathrm{T}$ and $\mathrm{B}$ lymphocyte proliferation for induction and long term maintenance of immunosuppression. In HCT, it is used for acute GVHD prophylaxis in the early post-HCT period [47], and then as primary immunosuppression in active chronic GVHD. Pulmonary toxicities are rare but do occur with sirolimus in this context, and may be severe and fatal $[48,49]$. The clinical presentation of sirolimus-induced lung injury is well described in the solid organ transplantation population, and includes cough (96\%), fatigue (83\%), fever $(67 \%)$, dyspnea $(33 \%)$, and hemoptysis $(8 \%)$. Physical exam is noted for hypoxemia $(50 \%)$ and inspiratory crackles $(50 \%)$. Radiographic findings on CT scan include patchy bilateral asymmetrical peripheral consolidations (COP-like pattern) $(79 \%)$, reticular and ground glass opacities (17\%) and lobar consolidation (4\%) 
Table 8.3 Pulmonary toxicity of immunosuppressant agents

\begin{tabular}{l|l}
\hline Immunosuppressant & Pulmonary toxicity \\
\hline Monoclonal antibodies & Capillary leak (noncardiogenic pulmonary edema), ARDS \\
\hline $\begin{array}{l}\text { Muromanab-CD3 (OKT3) } \\
\text { receptor) antibody }\end{array}$ & Capillary leak (noncardiogenic pulmonary edema) \\
\hline $\begin{array}{l}\text { Alemtuzumab anti-CD52 } \\
\text { antibody }\end{array}$ & Diffuse alveolar hemorrhage \\
\hline $\begin{array}{l}\text { Rituximab anti-CD-20 } \\
\text { antibody }\end{array}$ & $\begin{array}{l}\text { ARDS, diffuse alveolar hemorrhage interstitial pneumonitis, } \\
\text { cryptogenic organizing pneumonia, pulmonary fibrosis, } \\
\text { hypersensitivity pneumonitis }\end{array}$ \\
\hline Calcineurin inhibitors & Capillary leak (noncardiogenic pulmonary edema), ARDS \\
\hline Cyclosporine & Cryptogenic organizing pneumonia \\
\hline Tacrolimus & $\begin{array}{l}\text { Organizing pneumonia, diffuse alveolar hemorrhage, ARDS, } \\
\text { pulmonary alveolar proteinosis }\end{array}$ \\
\hline mTOR inhibitors & Interstitial pneumonitis, diffuse alveolar hemorrhage, ARDS \\
\hline Sirolimus & Pulmonary edema, ARDS, pulmonary fibrosis, bronchiectasis \\
\hline Everolimus & $\begin{array}{l}\text { Cryptogenic organizing pneumonia, diffuse alveolar } \\
\text { hemorrhage, interstitial pneumonitis,laryngeal edema, } \\
\text { vasculitis }\end{array}$ \\
\hline Mycophenolate mofetil
\end{tabular}

[50]. BAL reveals lymphocytic or eosinophilic alveolitis in up to $92 \%$ of cases. The predominant histologic patterns are organizing pneumonia, pulmonary hemorrhage, diffuse alveolar damage, and in a minority of cases, pulmonary alveolar proteinosis. The mainstay of treatment is discontinuation of the drug with or without corticosteroids $(1 \mathrm{mg} / \mathrm{kg} /$ day $)$, which results in complete resolution of symptoms within $2-4$ months. Less severe cases can be managed by a reduction in the sirolimus dose with close monitoring of serum levels, however, relapses have been reported with this approach [2].

\section{Pulmonary Alveolar Proteinosis}

Pulmonary alveolar proteinosis (PAP) is a rare disease characterized by the accumulation of surfactant lipids and protein in alveolar spaces resulting in gas exchange impairment. Primary, or autoimmune PAP, is due to the presence of autoantibodies against GM-CSF, which is a critical regulator of surfactant homeostasis. Secondary PAP comprises $7-10 \%$ of PAP cases, and occurs primarily in the setting of hematologic malignancies or unusual infections (e.g., Pneumocystis jirovecii or Nocardia spp). The underlying defect is thought to be due to qualitative and quantitative macrophage dysfunction, as by definition, there are no autoantibodies against GM-CSF, which distinguishes it from primary PAP [51]. In the context of HCT, secondary 
PAP is extremely rare but has been shown in autopsy series as a cause of undiagnosed premortem noninfectious pulmonary disease. PAP has been reported following autologous HCT, cord blood transplantation and cord blood transplantation in association with parainfluenza virus 3 [52]. There are cases of PAP which have resolved after chemotherapy or HCT for the underlying leukemia, presumably due to correction of the quantitative defect of macrophages present in marrow-infiltrating disease processes. Patients with PAP are at risk for infections, which may also confound the presentation and diagnosis in HCT recipients.

As with primary PAP, secondary PAP may be mild and self-limited or may progress to respiratory failure. Patients with secondary PAP present with progressive exertional dyspnea and nonproductive cough, a restrictive pattern and severely reduced diffusing capacity on pulmonary function tests. Computed tomography of the chest shows diffuse or patchy ground glass opacities, interlobular thickening, and subpleural sparing, or a "crazy paving" pattern, although this is more typical of primary PAP. Bronchoscopy reveals a milky, opaque lavage fluid containing large and foamy alveolar macrophages that stains positive with periodic acid-Schiff and is diagnostic in the appropriate clinical setting. The BAL may not reveal PAS+ material, as described in a recent case report [52], in which case surgical biopsy showing PAS+ material in architecturally preserved alveolar spaces may be required to confirm the diagnosis. Therapy of secondary PAP is directed at the underlying condition, i.e., treatment of infection or malignancy, in addition to supportive care. Corticosteroids are generally ineffective for this condition, and the mainstay of treatment is whole lung lavage. Exogenous GM-CSF for PAP after HCT is not effective, and the course of the disease may be self-limited.

\section{Pulmonary Vascular Disease}

Venous thromboembolism (VTE) is an under-recognized complication of HCT. In a retrospective study of $1514 \mathrm{HCT}$ recipients, the incidence of symptomatic VTE within the first 180 days post transplantation was $4.6 \%$ including $0.7 \%$ incidence of non-catheter-associated lower extremity DVT and $0.6 \%$ incidence of pulmonary emboli [53]. The median time after HCT admission to the development of noncatheter-associated lower extremity DVT and pulmonary embolism was 63 and 66 days, respectively. Risk factors for the development of VTE were prior VTE and GVHD. Thrombocytopenia was only partially protective against the development of VTE [53]. The safety and efficacy of thromboprophylaxis in HCT patients remains uncertain. In patients with thrombocytopenia, anticoagulant therapy for documented VTE should be accompanied by platelet transfusions to maintain a platelet count of $50 \times 10^{9} / \mathrm{L}$ or greater to reduce the risk of bleeding complications [2].

Pulmonary veno-occlusive disease (PVOD) is a rare, late-onset complication after HCT that presents with the insidious onset of fatigue and exertional dyspnea within 3-4 months after transplant. The physical examination typically shows hypoxemia and resting tachycardia consistent with pulmonary hypertension. Right 
heart catheterization demonstrates elevated pulmonary artery pressures with normal pulmonary capillary wedge pressure, and angiography is used to exclude pulmonary emboli as the etiology for the pulmonary hypertension. The diagnosis of PVOD is strongly supported by the triad of pulmonary artery hypertension, radiographic evidence of pulmonary edema, and normal pulmonary artery occlusion pressures; however, lung biopsy confirms the diagnosis by the presence of extensive and diffuse intimal proliferation and fibrosis of pulmonary venules [54]. Treatment consists of high-dose corticosteroids (methylprednisolone $2 \mathrm{mg} / \mathrm{kg} /$ day) with anecdotal success, but the overall prognosis of PVOD after HCT remains poor [55].

Pulmonary cytolytic thrombus (PCT) is seen exclusively in allogeneic HCT recipients and almost always in children. The incidence of PCT has been reported to range from 1.2 to $4 \%$ with a median onset at 3 months (range 1.3-11.3 months) after transplant. Clinical manifestations include fever, cough, and respiratory distress, and CT findings range from small, peripheral nodules to diffuse opacities. Diagnosis requires lung biopsy with histology characterized by vascular occlusions in distal pulmonary vessels, entrapment of leukocytes, endothelial disruption, and infarction of adjacent tissue. In a single-center, retrospective study, grades II to IV acute and chronic GVHD were independent risk factors for developing PCT. Treatment for PCT consists of systemic corticosteroids (prednisone 1-2 mg/ $\mathrm{kg} /$ day) until pulmonary symptoms resolve (typically within 2 weeks) followed by a steroid taper over 2-4 weeks. The strong association with acute and chronic GVHD, as well as the response to corticosteroid therapy, suggests that PCT is a manifestation of alloreactive lung injury. The prognosis with PCT is favorable, and there have been no reported deaths attributable to this entity $[56,57]$.

\section{Infectious Etiologies}

The profound alterations in immune status associated with bone marrow and stem cell transplantation renders this population vulnerable to severe opportunistic and community-acquired pneumonias that can precipitate acute respiratory failure (Fig. 8.1). In the first month after $\mathrm{HCT}$, neutropenia and immune suppression from management of acute early GVHD contribute to the infection risk predominantly due to bacterial pneumonia from nosocomial gram-positive and gram-negative organisms, herpes simplex virus, and Candida species. The early post-engraftment phase from 1 to 6 month post-HCT is characterized by impaired cellular immunity, continued immune suppression for GVHD, and interruptions in prophylaxis; opportunistic viral and fungal infections predominate. In the late post-engraftment phase, when immunosuppressive therapy is decreased in most patients, pulmonary infections are due more commonly to community-acquired organisms than opportunistic pathogens [2].

Because HCT recipients are particularly vulnerable to uncommon pathogens and suffer severe manifestations of common pathogens, much of what has been learned about these particular agents comes from the experience in this population. In this section we focus our review on the most important viral and fungal pathogens affecting HCT recipients in the contemporary era. 


\section{Cytomegalovirus}

Although specific antiviral therapy and preemptive treatment strategies have reduced the impact of cytomegalovirus (CMV) pneumonia in the early posttransplant period, CMV remains the most important opportunistic viral pathogen and cause of acute respiratory disease and mortality in HCT recipients. Prior to the implementation of CMV prophylaxis in the late 1990s, the incidence of CMV pneumonia was 10-30\% after allogeneic HCT and 1-6\% in autologous recipients. The use of ganciclovir for prophylaxis in the early posttransplant period has decreased the overall incidence to $5-8 \%$ and has increased the proportion of disease occurring in the late transplant period (>100 days) [58]. Risk factors for developing late onset disease include CMV antigenemia in the first 3 months, delayed lymphocyte engraftment, low CD4 counts, and acute graft-versus-host disease [59]. In a single center retrospective review of 421 cases of CMV pneumonia over a 25 year span, the overall survival of HCT recipients after CMV pneumonia onset was approximately $30 \%$; treatment with IV ganciclovir or foscarnet was associated with decreased overall mortality of patients with CMV pneumonia over time. Not surprisingly, coinfection with other lung pathogens was associated with increased overall mortality. Lymphopenia and the use of mechanical ventilation at the time of CMV onset were independently associated with an increased risk of 6-month CMV-attributable mortality [60].

The diagnosis of CMV pneumonia requires evidence of the virus by culture, cytology, immunohistochemistry, polymerase chain reaction (PCR), or direct fluorescent antibody methods in BAL fluid or lung biopsy, in conjunction with bilateral infiltrates on chest imaging. The use of rapid detection of CMV by shell vial culture is a highly sensitive method of detecting CMV that has improved the utility of bronchoscopy in making the diagnosis [14]. Quantitative PCR from the BAL may have higher sensitivity for CMV and is now used by many centers; however, lack of an appropriate cutoff for the viral load limits the interpretation of positive results. The presence of intranuclear inclusions on lung biopsy confirms the presence of CMV pneumonia, but lung biopsy is now rarely required to achieve diagnosis. The majority of patients with CMV pneumonia will have evidence of CMV reactivation in the blood [58].

First line antiviral therapy for CMV disease is IV ganciclovir, a nucleoside analog that inhibits DNA synthesis, with an induction phase of 7-21 days followed by at least 2 weeks of maintenance therapy. The major side effect of ganciclovir is neutropenia which limits its use in the pre-engraftment phase. High-dose intravenous pooled immunoglobulin or CMV-specific immunoglobulin administered as an adjunct to IV ganciclovir has been the standard of care for many years based on early open label trials, but recent analyses show no effect on attributable mortality [60]. Foscarnet, which inhibits CMV viral polymerase, is second line therapy in patients with known resistance to ganciclovir. Its major side effect is nephrotoxicity. Third line therapy is cidofovir, a competitive inhibitor of DNA polymerase, which has significant renal and hematologic toxicities [58]. 
Antiviral prophylaxis with gancyclovir has been shown in clinical trials to reduce the burden of disease early after transplant at the cost of prolonged neutropenia and increased bacterial and fungal infections as well as selection of ganciclovir-resistant strains of CMV. Most institutions use a preemptive strategy in which only those patients who show evidence of CMV reactivation in the blood by antigenemia or viral load on weekly screening are treated with ganciclovir to decrease the risk of CMV pneumonia [58].

\section{Community Respiratory Viruses}

Community respiratory viruses (CRV) cause considerable morbidity and mortality in the immunocompromised population when upper respiratory tract illness progresses to lower tract disease and acute respiratory failure. Risk factors for progression to pneumonia in HCT recipients include infection early after transplantation, allogeneic HCT, myeloablative conditioning, GVHD, and lymphopenia [61]. The majority of clinically relevant CRV can be diagnosed with nasal washing, nasopharyngeal swabs, or BAL by rapid antigen detection or RT-PCR methods. There are few specific antiviral agents with efficacy against CRV and management is primarily supportive. HCT recipients may shed virus for prolonged periods of time [62].

CRVs include influenza, respiratory syncytial virus (RSV), and parainfluenza serotypes-1 and 2, which have their peak primarily in the winter months, and parainfluenza serotype-3 and adenovirus, which occur year round. Patterns of influenza infection in HCT recipients reflect the seasonal occurrence in the community, with an incidence of seasonal influenza infection after HCT of $1-4 \%$ and a mortality rate of $15-28 \%$ in the setting of pneumonia [61]. Due to the prevalence of resistance to the M2 inhibitors (amantadine and rimantadine), neuraminidase inhibitors (oseltamavir and zanamivir) are used in the immunosuppressed host with suspected or documented influenza [63].

Parainfluenza virus is a major cause of laryngotracheobronchitis in children; parainfluenza serotype-3 (PIV-3) is the most frequently found in immunocompromised patients. Almost half of HCT recipients with PIV infection progress to lower respiratory tract infection with a mortality rate of $17 \%$ [64]. Although sometimes used, ribarivin and IVIG have not been shown to be efficacious in treating PIV pneumonia. DAS181 is a novel sialidase fusion protein currently being tested in clinical trials for treating PIV disease in severely immunocompromised individuals [63].

Newly discovered respiratory viruses of clinical significance that have emerged within the past decade include human metapneumovirus (HMPV), human bocavirus, and new coronaviruses. HMPV was first reported in 2001 and has an associated mortality of 33-40\% for lower respiratory tract disease [61] HMPV has been detected in HCT recipients with fulminant respiratory failure initially attributed to IPS [65].

Respiratory syncytial virus (RSV) is one of the leading causes of viral pneumonia in HCT recipients, affecting 24-31\% of HCT recipients with a documented respiratory viral infection [62]. Usually presenting as an upper respiratory tract 
infection with rhinorrhea, sinus congestion and a sore throat, RSV infection can progress to bronchiolitis, pneumonitis, and pneumonia. Patients who have not yet engrafted are at highest risk for progression to lower tract disease, and once pneumonia is established, mortality is $43 \%$ [62]. Risk factors for mortality include hypoxemia, steroids at the time of diagnosis, or mechanical ventilation [66]. In survivors of HCT, lower respiratory tract infection with RSV in the first 100 day is associated with increased risk of developing airflow decline (OR 3.6) [67], which may be recognized as BOS. Uncontrolled studies suggest that treatment of RSV lower respiratory tract infection with aerosolized ribavirin and RSV-Ig can reduce mortality to $<20 \%$ if initiated before the onset of respiratory failure [62]. The novel compound GS-5806, an RSV entry inhibitor, reduces the viral load and severity of clinical disease in healthy adult volunteers and is currently in phase II clinical trials to treat RSV in HCT recipients [68].

\section{Invasive Fungal Disease}

The epidemiology of invasive fungal infection (IFI) continues to evolve with advances in detection, prophylaxis and treatment. When recently revised definitions for proven and probable invasive fungal disease [69] are applied, the incidence of all IFI is $14 \%$ in allogeneic HCT recipients. Aspergillosis accounts for $50 \%$ of the IFI, followed by candidiasis and mucormycosis [70]. Widespread use of voriconazole may be contributing to emergence of mold infections with decreased susceptibility to voriconazole, including Mucorales spp. [71].

Manifestations of Aspergillus in the HCT population include airway colonization, tracheobronchitis, pneumonia, sinusitis or disseminated disease. Symptoms of pulmonary invasive aspergillosis (IA) include dyspnea, fever, productive cough, chest pain and hemoptysis; patients may also be asymptomatic [2]. After recovery from neutropenia, $64 \%$ of allogeneic HCT recipients with invasive filamentous fungal infection presented with dyspnea but only $32 \%$ were febrile [72]. Mortality at 3 months from the time of IA diagnosis ranges from $53.8 \%$ of autologous recipients to $84.6 \%$ for unrelated donor recipients and does not differ for those with earlyversus late-onset infections [73, 74].

The gold standard for the diagnosis of IA is biopsy with culture in the setting of compatible clinical and radiographic features; however biopsy is now rarely performed to confirm IA. Galactomannan, a fungal polysaccharide specific to Aspergillus spp, is a widely used biomarker for the detection of IA from both the serum and BAL fluid. The serum galactomannan assay has a sensitivity and specificity of 82 and $86 \%$, respectively, for the detection of IA in HCT recipients [75]. Galactomannan testing of BAL has a sensitivity of $60-82 \%$ and a specificity of 95\%. PCR-based methods for the detection of Aspergillus are not yet standardized for clinical use although published studies indicate that BAL analysis using quantitative RT-PCR has a sensitivity of $67-77 \%$ and specificity of 90-100\% [76]. 
The approach to treatment of IA should involve reducing the level of immunosuppression to the extent possible in addition to the use of an antifungal agent with appropriate efficacy and minimal toxicity profile. It is important to recognize that all clinically relevant azole antimicrobials inhibit cytochrome $\mathrm{P} 450$ isoenzyme activity to varying degrees resulting in increased serum concentrations of cyclosporine, tacrolimus, sirolimus and everolimus that could lead to neurotoxicity and/or nephrotoxicity. These medications must be dose-adjusted when the patient requires azole treatment for IFI [2]. Voriconazole, a broad-spectrum triazole derivative that became available in 2002, is the agent of choice for the treatment of IA based on its superior efficacy and survival benefit in comparison to amphotericin [77]. Liposomal amphotericin B is an alternative in patients who are azole intolerant. Echinocandins (caspofungin, micafungin, anidulafungin) are also an option for the treatment of IA and have very low potential for drug interactions although tacrolimus levels may be reduced. Surgical resection for focally invasive disease that is refractory to medical therapy can be considered in neutropenic patients. Inhaled liposomal amphotericin $\mathrm{B}$, in addition to systemic antifungals, can be used for the treatment of fungal tracheobronchitis [2].

Mucormycosis is an aggressive infection with high mortality associated with prolonged neutropenia. It accounts for $8 \%$ of IFI in HCT recipients, most often as a late complication ( $>3$ months after transplantation) with pulmonary involvement in over half of cases. The overall mortality rate among HCT recipients is at least $75 \%$ [78]. First line therapy is liposomal amphotericin B for at least 6-8 weeks and extensive early surgical debridement. A combination of liposomal amphotericin and an echinocandin may be considered in cases that are refractory to first line therapy. Isavuconazole is a promising new extended spectrum triazole with excellent oral bioavailability and a low side effect profile, which may have utility as primary therapy against invasive mucormycosis and other IFI [79].

\section{Key Points}

- Acute respiratory disease is a significant contributor to the morbidity and mortality of hematopoietic cell transplantation.

- The differential diagnosis of pulmonary disease depends on the time frame after HCT and the patient's immune status.

- A spectrum of noninfectious acute lung injuries that develop in the early posttransplantation period falls under the category of the idiopathic pneumonia syndrome (IPS). Late-onset lung injury usually manifests as cryptogenic organizing pneumonia.

- Other noninfectious pulmonary complications include pulmonary alveolar proteinosis, pulmonary vascular disease, and drug toxicities.

- The epidemiology of acute lung injury and classic infectious etiologies of acute respiratory disease in this population has changed since the advent of improved supportive care, diagnostic detection, and treatments. 


\section{References}

1. Gooley TA, Chien JW, Pergam SA, Hingorani S, Sorror ML, Boeckh M, et al. Reduced mortality after allogeneic hematopoietic-cell transplantation. N Engl J Med. 2010;363(22): 2091-101.

2. Madtes DK. Pulmonary complications of stem cell and solid organ transplantation. In: Broaddus VC, editor. Murray and Nadel's textbook of respiratory medicine, vol. 2. 6th ed. Philadelphia, PA: Saunders; 2016. p. 1612-23.e8.

3. Afessa B, Azoulay E. Critical care of the hematopoietic stem cell transplant recipient. Crit Care Clin. 2010;26(1):133-50.

4. Ho VT, Weller E, Lee SJ, Alyea EP, Antin JH, Soiffer RJ. Prognostic factors for early severe pulmonary complications after hematopoietic stem cell transplantation. Biol Blood Marrow Transplant. 2001;7(4):223-9.

5. Rubenfeld GD, Crawford SW. Withdrawing life support from mechanically ventilated recipients of bone marrow transplants: a case for evidence-based guidelines. Ann Intern Med. 1996;125(8):625-33.

6. Naeem N, Reed MD, Creger RJ, Youngner SJ, Lazarus HM. Transfer of the hematopoietic stem cell transplant patient to the intensive care unit: does it really matter? Bone Marrow Transplant. 2006;37(2):119-33.

7. The Acute Respiratory Distress Syndrome Network. Ventilation with lower tidal volumes as compared with traditional tidal volumes for acute lung injury and the acute respiratory distress syndrome. N Engl J Med. 2000;342(18):1301-8.

8. Rivers E, Nguyen B, Havstad S, Ressler J, Muzzin A, Knoblich B, et al. Early goal-directed therapy in the treatment of severe sepsis and septic shock. $\mathrm{N}$ Engl $\mathrm{J}$ Med. 2001;345(19):1368-77.

9. Soubani AO, Kseibi E, Bander JJ, Klein JL, Khanchandani G, Ahmed HP, et al. Outcome and prognostic factors of hematopoietic stem cell transplantation recipients admitted to a medical ICU. Chest. 2004;126(5):1604-11.

10. Kew AK, Couban S, Patrick W, Thompson K, White D. Outcome of hematopoietic stem cell transplant recipients admitted to the intensive care unit. Biol Blood Marrow Transplant. 2006;12(3):301-5.

11. Lengline E, Chevret S, Moreau AS, Pene F, Blot F, Bourhis JH, et al. Changes in intensive care for allogeneic hematopoietic stem cell transplant recipients. Bone Marrow Transplant. 2015;50(6):840-5.

12. Pene F, Aubron C, Azoulay E, Blot F, Thiery G, Raynard B, et al. Outcome of critically ill allogeneic hematopoietic stem-cell transplantation recipients: a reappraisal of indications for organ failure supports. J Clin Oncol. 2006;24(4):643-9.

13. Harris B, Lowy FD, Stover DE, Arcasoy SM. Diagnostic bronchoscopy in solid-organ and hematopoietic stem cell transplantation. Ann Am Thorac Soc. 2013;10(1):39-49.

14. Crawford SW, Bowden RA, Hackman RC, Gleaves CA, Meyers JD, Clark JG. Rapid detection of cytomegalovirus pulmonary infection by bronchoalveolar lavage and centrifugation culture. Ann Intern Med. 1988;108(2):180-5.

15. Patel NR, Lee PS, Kim JH, Weinhouse GL, Koziel H. The influence of diagnostic bronchoscopy on clinical outcomes comparing adult autologous and allogeneic bone marrow transplant patients. Chest. 2005;127(4):1388-96.

16. Hofmeister CC, Czerlanis C, Forsythe S, Stiff PJ. Retrospective utility of bronchoscopy after hematopoietic stem cell transplant. Bone Marrow Transplant. 2006;38(10):693-8.

17. Shannon VR, Andersson BS, Lei X, Champlin RE, Kontoyiannis DP. Utility of early versus late fiberoptic bronchoscopy in the evaluation of new pulmonary infiltrates following hematopoietic stem cell transplantation. Bone Marrow Transplant. 2010;45(4):647-55.

18. White DA, Wong PW, Downey R. The utility of open lung biopsy in patients with hematologic malignancies. Am J Respir Crit Care Med. 2000;161(3 Pt 1):723-9. 
19. Crawford SW, Hackman RC, Clark JG. Open lung biopsy diagnosis of diffuse pulmonary infiltrates after marrow transplantation. Chest. 1988;94(5):949-53.

20. Crawford SW, Hackman RC, Clark JG. Biopsy diagnosis and clinical outcome of persistent focal pulmonary lesions after marrow transplantation. Transplantation. 1989;48(2):266-71.

21. Cheng GS, Stednick Z, Madtes DK, McDonald G, Boeckh M, Pergam SA. Changing trends in the use of surgical biopsy for diagnosis of pulmonary disease in hematopoietic cell transplant recipients. 2013 BMT Tandem Meetings; Salt Lake City, UT. Biol Blood Marrow Transplant. 2013;19:S297.

22. Chellapandian D, Lehrnbecher T, Phillips B, Fisher BT, Zaoutis TE, Steinbach WJ, et al. Bronchoalveolar lavage and lung biopsy in patients with cancer and hematopoietic stem-cell transplantation recipients: a systematic review and meta-analysis. $\mathrm{J}$ Clin Oncol. 2015;33(5):501-9.

23. Seo S, Renaud C, Kuypers JM, Chiu CY, Huang ML, Samayoa E, et al. Idiopathic pneumonia syndrome after hematopoietic cell transplantation: evidence of occult infectious etiologies. Blood. 2015;125(24):3789-97.

24. Razonable RR, Fanning C, Brown RA, Espy MJ, Rivero A, Wilson J, et al. Selective reactivation of human herpesvirus 6 variant a occurs in critically ill immunocompetent hosts. J Infect Dis. 2002;185(1):110-3.

25. Panoskaltsis-Mortari A, Griese M, Madtes DK, Belperio JA, Haddad IY, Folz RJ, et al. An official American Thoracic Society research statement: noninfectious lung injury after hematopoietic stem cell transplantation: idiopathic pneumonia syndrome. Am J Respir Crit Care Med. 2011;183(9):1262-79.

26. Fukuda T, Hackman RC, Guthrie KA, Sandmaier BM, Boeckh M, Maris MB, et al. Risks and outcomes of idiopathic pneumonia syndrome after nonmyeloablative and conventional conditioning regimens for allogeneic hematopoietic stem cell transplantation. Blood. 2003;102(8):2777-85.

27. Vande Vusse LK, Madtes DK, Guthrie KA, Gernsheimer TB, Curtis JR, Watkins TR. The association between red blood cell and platelet transfusion and subsequently developing idiopathic pneumonia syndrome after hematopoietic stem cell transplantation. Transfusion. 2014;54(4):1071-80.

28. Marr KA. Fungal infections in hematopoietic stem cell transplant recipients. Med Mycol. 2008;46(4):293-302.

29. Yanik GA, Grupp SA, Pulsipher MA, Levine JE, Schultz KR, Wall DA, et al. TNF-receptor inhibitor therapy for the treatment of children with idiopathic pneumonia syndrome. A joint Pediatric Blood and Marrow Transplant Consortium and Children's Oncology Group Study (ASCT0521). Biol Blood Marrow Transplant. 2015;21(1):67-73.

30. Yanik GA, Horowitz MM, Weisdorf DJ, Logan BR, Ho VT, Soiffer RJ, et al. Randomized, double-blind, placebo-controlled trial of soluble tumor necrosis factor receptor: enbrel (etanercept) for the treatment of idiopathic pneumonia syndrome after allogeneic stem cell transplantation: blood and marrow transplant clinical trials network protocol. Biol Blood Marrow Transplant. 2014;20(6):858-64.

31. Gorak E, Geller N, Srinivasan R, Espinoza-Delgado I, Donohue T, Barrett AJ, et al. Engraftment syndrome after nonmyeloablative allogeneic hematopoietic stem cell transplantation: incidence and effects on survival. Biol Blood Marrow Transplant. 2005;11(7):542-50.

32. Wilczynski SW, Erasmus JJ, Petros WP, Vredenburgh JJ, Folz RJ. Delayed pulmonary toxicity syndrome following high-dose chemotherapy and bone marrow transplantation for breast cancer. Am J Respir Crit Care Med. 1998;157(2):565-73.

33. Lee SM, Park JJ, Sung SH, Kim Y, Lee KE, Mun YC, et al. Acute fibrinous and organizing pneumonia following hematopoietic stem cell transplantation. Korean $\mathrm{J}$ Intern Med. 2009;24(2):156-9.

34. Beasley MB, Franks TJ, Galvin JR, Gochuico B, Travis WD. Acute fibrinous and organizing pneumonia: a histological pattern of lung injury and possible variant of diffuse alveolar damage. Arch Pathol Lab Med. 2002;126(9):1064-70. 
35. Bhatti S, Hakeem A, Torrealba J, McMahon JP, Meyer KC. Severe acute fibrinous and organizing pneumonia (AFOP) causing ventilatory failure: successful treatment with mycophenolate mofetil and corticosteroids. Respir Med. 2009;103(11):1764-7.

36. Freudenberger TD, Madtes DK, Curtis JR, Cummings P, Storer BE, Hackman RC. Association between acute and chronic graft-versus-host disease and bronchiolitis obliterans organizing pneumonia in recipients of hematopoietic stem cell transplants. Blood. 2003;102(10):3822-8.

37. Yanik G, Kitko C. Management of noninfectious lung injury following hematopoietic cell transplantation. Curr Opin Oncol. 2013;25(2):187-94.

38. Nakasone H, Onizuka M, Suzuki N, Fujii N, Taniguchi S, Kakihana K, et al. Pre-transplant risk factors for cryptogenic organizing pneumonia/bronchiolitis obliterans organizing pneumonia after hematopoietic cell transplantation. Bone Marrow Transplant. 2013;48(10):1317-23.

39. Pipavath SN, Chung JH, Chien JW, Godwin JD. Organizing pneumonia in recipients of hematopoietic stem cell transplantation: CT features in 16 patients. J Comput Assist Tomogr. 2012;36(4):431-6.

40. Cottin V, Cordier JF. Cryptogenic organizing pneumonia. Semin Respir Crit Care Med. 2012;33(5):462-75.

41. Stover DE, Mangino D. Macrolides: a treatment alternative for bronchiolitis obliterans organizing pneumonia? Chest. 2005;128(5):3611-7.

42. Au BK, Au MA, Chien JW. Bronchiolitis obliterans syndrome epidemiology after allogeneic hematopoietic cell transplantation. Biol Blood Marrow Transplant. 2011;17(7):1072-8.

43. Clark JG, Crawford SW, Madtes DK, Sullivan KM. Obstructive lung disease after allogeneic marrow transplantation. Clinical presentation and course. Ann Intern Med. 1989;111(5):368-76.

44. Lane AA, Armand P, Feng Y, Neuberg DS, Abramson JS, Brown JR, et al. Risk factors for development of pneumonitis after high-dose chemotherapy with cyclophosphamide, BCNU and etoposide followed by autologous stem cell transplant. Leuk Lymphoma. 2012;53(6):1130-6.

45. Abushamaa AM, Sporn TA, Folz RJ. Oxidative stress and inflammation contribute to lung toxicity after a common breast cancer chemotherapy regimen. Am J Physiol Lung Cell Mol Physiol. 2002;283(2):L336-45.

46. Malik SW, Myers JL, DeRemee RA, Specks U. Lung toxicity associated with cyclophosphamide use. Two distinct patterns. Am J Respir Crit Care Med. 1996;154(6 Pt 1):1851-6.

47. Cutler C, Logan B, Nakamura R, Johnston L, Choi S, Porter D, et al. Tacrolimus/sirolimus vs tacrolimus/methotrexate as GVHD prophylaxis after matched, related donor allogeneic HCT. Blood. 2014;124(8):1372-7.

48. Garrod AS, Goyal RK, Weiner DJ. Sirolimus-induced interstitial lung disease following pediatric stem cell transplantation. Pediatr Transplant. 2015;19(3):E75-7.

49. Patel AV, Hahn T, Bogner PN, Loud PA, Brown K, Paplham P, et al. Fatal diffuse alveolar hemorrhage associated with sirolimus after allogeneic hematopoietic cell transplantation. Bone Marrow Transplant. 2010;45(8):1363-4.

50. Champion L, Stern M, Israel-Biet D, Mamzer-Bruneel MF, Peraldi MN, Kreis H, et al. Brief communication: sirolimus-associated pneumonitis: 24 cases in renal transplant recipients. Ann Intern Med. 2006;144(7):505-9.

51. Trapnell BC, Whitsett JA, Nakata K. Pulmonary alveolar proteinosis. N Engl J Med. 2003;349(26):2527-39.

52. Pidala J, Khalil F, Fernandez H. Pulmonary alveolar proteinosis following allogeneic hematopoietic cell transplantation. Bone Marrow Transplant. 2011;46(11):1480-3.

53. Gerber DE, Segal JB, Levy MY, Kane J, Jones RJ, Streiff MB. The incidence of and risk factors for venous thromboembolism (VTE) and bleeding among 1514 patients undergoing hematopoietic stem cell transplantation: implications for VTE prevention. Blood. 2008;112(3):504-10.

54. Mandel J, Mark EJ, Hales CA. Pulmonary veno-occlusive disease. Am J Respir Crit Care Med. 2000;162(5):1964-73.

55. Hackman RC, Madtes DK, Petersen FB, Clark JG. Pulmonary venoocclusive disease following bone marrow transplantation. Transplantation. 1989;47(6):989-92. 
56. Woodard JP, Gulbahce E, Shreve M, Steiner M, Peters C, Hite S, et al. Pulmonary cytolytic thrombi: a newly recognized complication of stem cell transplantation. Bone Marrow Transplant. 2000;25(3):293-300.

57. Peters A, Manivel JC, Dolan M, Gulbahce HE, Baker KS, Verneris MR. Pulmonary cytolytic thrombi after allogeneic hematopoietic cell transplantation: a further histologic description. Biol Blood Marrow Transplant. 2005;11(6):484-5.

58. Travi G, Pergam SA. Cytomegalovirus pneumonia in hematopoietic stem cell recipients. J Intensive Care Med. 2014;29(4):200-12.

59. Boeckh M, Leisenring W, Riddell SR, Bowden RA, Huang ML, Myerson D, et al. Late cytomegalovirus disease and mortality in recipients of allogeneic hematopoietic stem cell transplants: importance of viral load and T-cell immunity. Blood. 2003;101(2):407-14.

60. Erard V, Guthrie KA, Seo S, Smith J, Huang M, Chien J, et al. Reduced mortality of cytomegalovirus pneumonia after hematopoietic cell transplantation due to antiviral therapy and changes in transplantation practices. Clin Infect Dis. 2015;61(1):31-9.

61. Renaud C, Campbell AP. Changing epidemiology of respiratory viral infections in hematopoietic cell transplant recipients and solid organ transplant recipients. Curr Opin Infect Dis. 2011;24(4):333-43.

62. Kim YJ, Boeckh M, Englund JA. Community respiratory virus infections in immunocompromised patients: hematopoietic stem cell and solid organ transplant recipients, and individuals with human immunodeficiency virus infection. Semin Respir Crit Care Med. 2007;28(2):222-42.

63. Chemaly RF, Shah DP, Boeckh MJ. Management of respiratory viral infections in hematopoietic cell transplant recipients and patients with hematologic malignancies. Clin Infect Dis. 2014;59 Suppl 5:S344-51.

64. Chemaly RF, Hanmod SS, Rathod DB, Ghantoji SS, Jiang Y, Doshi A, et al. The characteristics and outcomes of parainfluenza virus infections in 200 patients with leukemia or recipients of hematopoietic stem cell transplantation. Blood. 2012;119(12):2738-45. quiz 969.

65. Englund JA, Boeckh M, Kuypers J, Nichols WG, Hackman RC, Morrow RA, et al. Brief communication: fatal human metapneumovirus infection in stem-cell transplant recipients. Ann Intern Med. 2006;144(5):344-9.

66. Renaud C, Xie H, Seo S, Kuypers J, Cent A, Corey L, et al. Mortality rates of human metapneumovirus and respiratory syncytial virus lower respiratory tract infections in hematopoietic cell transplantation recipients. Biol Blood Marrow Transplant. 2013;19(8):1220-6.

67. Erard V, Chien JW, Kim HW, Nichols WG, Flowers ME, Martin PJ, et al. Airflow decline after myeloablative allogeneic hematopoietic cell transplantation: the role of community respiratory viruses. J Infect Dis. 2006;193(12):1619-25.

68. DeVincenzo JP, Whitley RJ, Mackman RL, Scaglioni-Weinlich C, Harrison L, Farrell E, et al. Oral GS-5806 activity in a respiratory syncytial virus challenge study. N Engl J Med. 2014;371(8):711-22.

69. De Pauw B, Walsh TJ, Donnelly JP, Stevens DA, Edwards JE, Calandra T, et al. Revised definitions of invasive fungal disease from the European Organization for Research and Treatment of Cancer/Invasive Fungal Infections Cooperative Group and the National Institute of Allergy and Infectious Diseases Mycoses Study Group (EORTC/MSG) Consensus Group. Clin Infect Dis. 2008;46(12): 1813-21.

70. Corzo-Leon DE, Satlin MJ, Soave R, Shore TB, Schuetz AN, Jacobs SE, et al. Epidemiology and outcomes of invasive fungal infections in allogeneic haematopoietic stem cell transplant recipients in the era of antifungal prophylaxis: a single-centre study with focus on emerging pathogens. Mycoses. 2015;58(6):325-36.

71. Ziakas PD, Kourbeti IS, Mylonakis E. Systemic antifungal prophylaxis after hematopoietic stem cell transplantation: a meta-analysis. Clin Ther. 2014;36(2):292-306 e1.

72. Shaukat A, Bakri F, Young P, Hahn T, Ball D, Baer MR, et al. Invasive filamentous fungal infections in allogeneic hematopoietic stem cell transplant recipients after recovery from neutropenia: clinical, radiologic, and pathologic characteristics. Mycopathologia. 2005;159(2):181-8.

73. Morgan J, Wannemuehler KA, Marr KA, Hadley S, Kontoyiannis DP, Walsh TJ, et al. Incidence of invasive aspergillosis following hematopoietic stem cell and solid organ transplantation: 
interim results of a prospective multicenter surveillance program. Med Mycol. 2005;43 Suppl 1:S49-58.

74. Singh N, Paterson DL. Aspergillus infections in transplant recipients. Clin Microbiol Rev. 2005;18(1):44-69.

75. Pfeiffer CD, Fine JP, Safdar N. Diagnosis of invasive aspergillosis using a galactomannan assay: a meta-analysis. Clin Infect Dis. 2006;42(10):1417-27.

76. Wengenack NL, Binnicker MJ. Fungal molecular diagnostics. Clin Chest Med. 2009;30(2):391408. viii.

77. Herbrecht R, Denning DW, Patterson TF, Bennett JE, Greene RE, Oestmann JW, et al. Voriconazole versus amphotericin B for primary therapy of invasive aspergillosis. N Engl J Med. 2002;347(6):408-15.

78. Lanternier F, Sun HY, Ribaud P, Singh N, Kontoyiannis DP, Lortholary O. Mucormycosis in organ and stem cell transplant recipients. Clin Infect Dis. 2012;54(11):1629-36.

79. Miceli MH, Kauffman CA. Isavuconazole: a new broad-spectrum triazole antifungal agent. Clin Infect Dis. 2015;61(10):1558-65. 